\title{
Carta ao Editor
}

\section{PLASMOCITOMAS CUTÂNEOS METASTÁTICOS}

\author{
Diogo Matos', João Alves', Hugo Barreiros ${ }^{2}$, Ricardo Coelho ${ }^{3}$, Elvira Bártolo ${ }^{4}$, Fernanda Vargas ${ }^{5}$ \\ 'Interno do Internato Complementar de Dermatologia e Venereologia/ Resident, Dermatology and Venereology, \\ Hospital Garcia de Orta, Almada, Portugal \\ 2Dermatologista/Dermatologist, Centro Dermatologia Epidermis, Instituto CUF, Porto, Portugal \\ ${ }^{3}$ Assistente Hospitalar de Dermatologia e Venereologia/Consultant, Dermatology and Venereology, Hospital Garcia de \\ Orta, Almada, Portugal \\ ${ }^{4}$ Chefe de Serviço de Dermatologia e Venereologia, Directora do Serviço de Dermatologia e Venereologia/ Chief and \\ Head of Dermatology and Venereology Department \\ Hospital Garcia de Orta, Almada, Portugal \\ ${ }^{5}$ Assistente Hospitalar de Hematologia/Consultant, Haematology, Hospital Garcia de Orta, Almada, Portugal
}

PALAVRAS-CHAVE - Plasmocitoma; Neoplasias da pele; Mieloma múltiplo.

\section{CUTANEOUS METASTATIC PLASMACYTOMAS}

KEY-WORDS - Plasmacytoma; Skin neoplasms; Multiple myeloma.

\begin{abstract}
Conflitos de interesse: Os autores declaram não possuir conflitos de interesse.
No conflicts of interest.

Suporte financeiro: $O$ presente trabalho não foi suportado por nenhum subsídio ou bolsa.

No sponsorship or scholarship granted.

Direito à privacidade e consentimento escrito / Privacy policy and informed consent: Os autores declaram que pediram consentimento ao doente para usar as imagens no artigo. The authors declare that the patient gave written informed consent for the use of its photos in this article.
\end{abstract}

Recebido/Received - Maio/May 2014; Aceite/Accepted - Junho/June 2014

Por decisão dos autores, este artigo não foi redigido de acordo com os termos do novo Acordo Ortográfico.

\section{Correspondência: \\ Dr. Diogo Matos \\ Serviço de Dermatovenereologia \\ Hospital Garcia de Orta \\ Avenida Torrado da Silva \\ 2801-951 Almada, Portugal \\ Email: diogomatos.pt@gmail.com}

Mulher de 68 anos com história de mieloma múltiplo IgG K estadio IIIA, para o qual estava a ser tratada, na consulta de hematologia do nosso hospital, com esquema combinado de quimioterapia (melphalan, prednisolona e talidomida) havia 16 meses, é enviada à nossa consulta por dermatose assintomática com 2 meses de evolução, caracterizada por 3 nódulos violáceos de consistência firme, aderentes aos planos profundos, medindo 4-6 cm de diâmetro, localizados na região parietal direita, o maior dos quais e mais posterior, com ulceração e formação de crostas amareladas aderentes ao seu polo superior (Fig. 1a). Para além destes tinha vários outros nódulos de menores dimensões no restante couro cabeludo e antebraço direito. $\mathrm{Na}$ anamnese não foi apurada qualquer outra sintomatologia, nomeadamente febre ou anorexia. $O$ restante exame objectivo 


\section{Carta ao Editor}

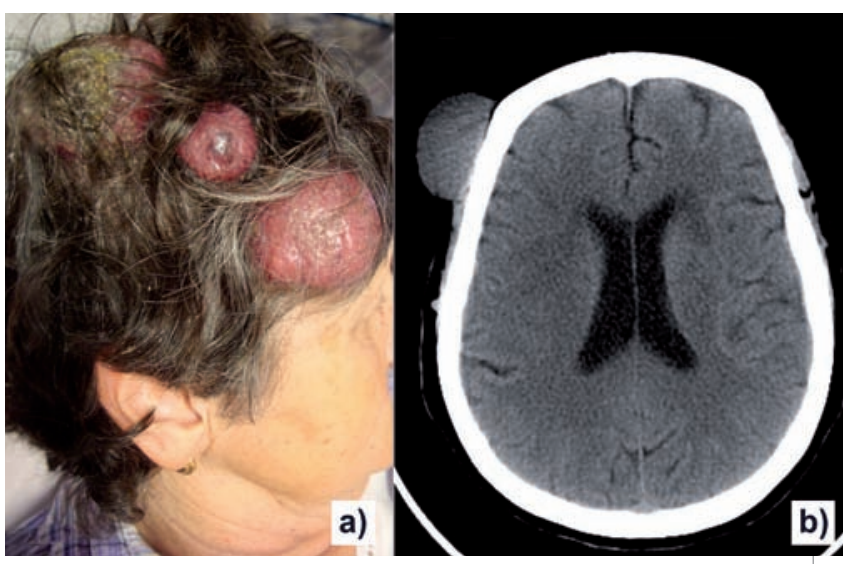

Fig. 1 - a) Nódulos parietais à direita. b) TC álica não mostrando lesão osteolítica subjacente à lesão cutânea.

era normal, nomeadamente não eram evidentes adenopatias. Não havia também evidência laboratorial de progressão do mieloma múltiplo, o qual se encontrava controlado com o tratamento em vigor. Na TC crânio-encefálica não eram visíveis lesões ósseas subjacentes às cutâneas (Fig. 1b).

O exame histopatológico da biopsia de um dos nódulos parietais mostrou um infiltrado denso e difuso em toda a derme, composto por plasmócitos típicos e atípi$\cos$ (Fig.s 2 a,b). $\bigcirc$ estudo imunohistoquímico mostrou positividade para CD138 e expressão restrita de cadeias leves K (Fig.s 2 c-e).

Com estes dados, e considerando o mieloma múltiplo previamente conhecido, fez-se o diagnóstico de plasmocitomas cutâneos metastáticos.

Apesar da optimização terapêutica com bortezomib, assistiu-se à progressão da doença cutânea. Concomitantemente, a doença sistémica evolviu com anemia e trombocitopénia de difícil controlo. A doente morreu, na sequência de complicações infecciosas, 4 meses após o aparecimento das lesões cutâneas.

O plasmocitoma é uma entidade clínica rara e resulta
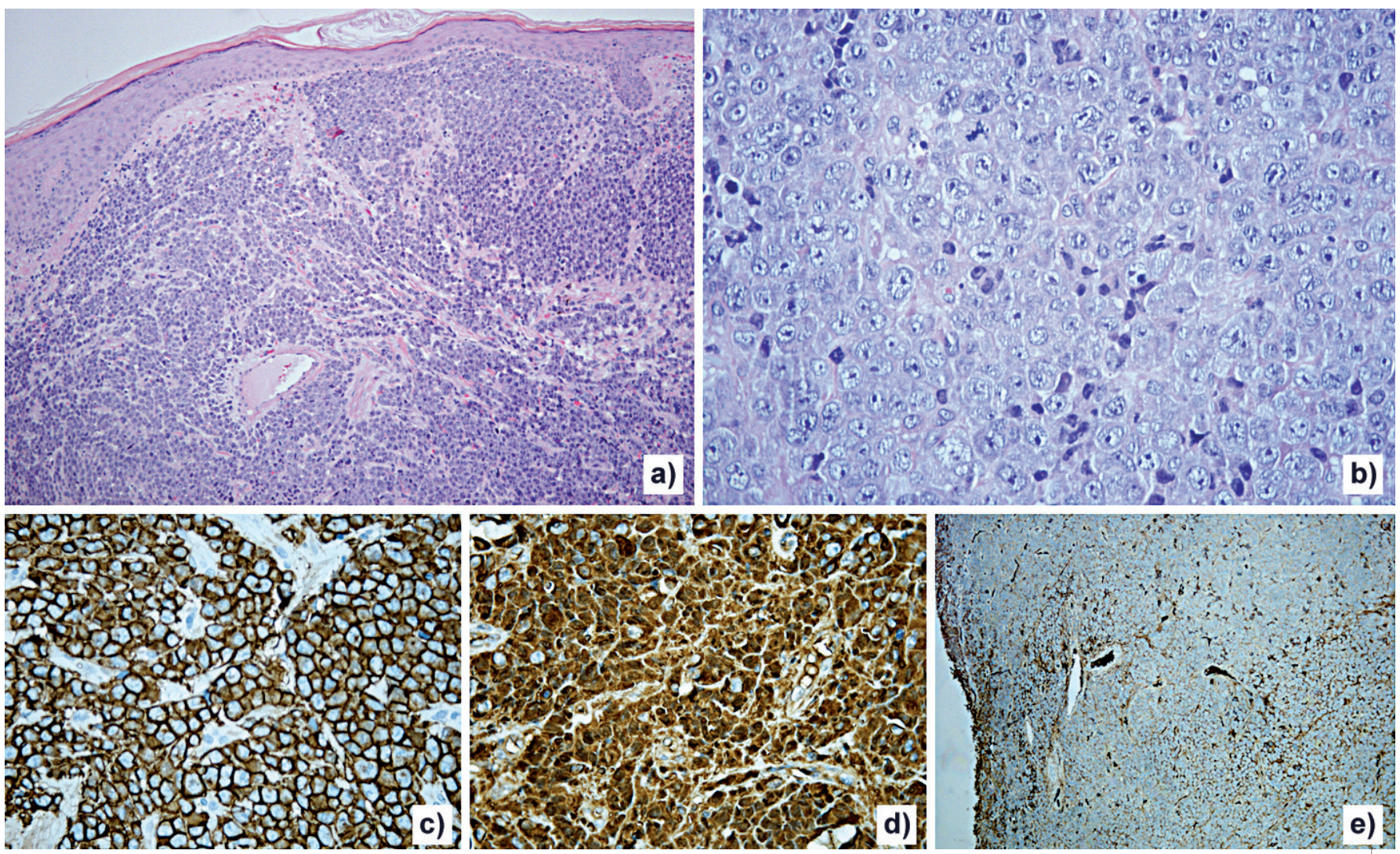

Fig 2 - c)

c) Imunohistoulmica

100); b) P

d) Imunohistoquímica positiva para cadeias $K$

e) Imunohistoquímica negativa para

cadeias $\lambda$ 


\section{Carta ao Editor}

de um envolvimento cutâneo primário ou secundário por uma proliferação clonal de plasmócitos. O plasmocitoma cutâneo primário, uma forma de plasmocitoma extramedular, é extremamente raro. Os plasmocitomas cutâneos metastáticos podem surgir, secundariamente, no contexto de uma neoplasia dos plasmócitos: mieloma múltiplo, plasmocitoma ósseo solitário, leucemia de plasmócitos ou plasmocitoma extramedular primariamente extracutâneo. O mieloma múltiplo, dada a sua maior prevalência, é a causa mais frequente. Os plasmocitomas metastáticos ocorrem tipicamente em estádios avançados do mieloma múltiplo, reflectindo uma carga tumoral elevada e, consequentemente, indiciam um mau prognóstico. Por via de regra, as lesões de plasmocitoma resultam da extensão directa para a pele de lesões ósseas osteolíticas. No entanto, em casos raros, como o da nossa doente, pode surgir independentemente do envolvimento ósseo comportando-se como uma verdadeira doença metastática, podendo, ainda mais raramente, ser a primeira manifestação de mieloma múltiplo ${ }^{1-7}$. Geralmente caracterizam-se por placas ou nódulos eritemato-violáceos, sendo possível haver apenas envolvimento subcutâneo. No entanto, estão descritas outras apresentações clínicas, tais como lesões "erisipela-like"8. Qualquer área do tegumento pode ser afectada, contudo o tronco, o couro cabeludo e a face são as localizações mais reportadas, provavelmente por ser nestas que mais frequentemente se localizam as lesões osteolíticas no contexto do mieloma múltiplo.

O nosso caso clínico ilustra o valor prognóstico da identificação de plasmocitomas cutâneos metastáticos, já que estes foram a primeira manifestação dum mieloma múltiplo em estadio terminal, cujo curso clínico rapidamente de deteriorou.

\section{REFERÊNCIAS}

1. Patterson JW, Parsons JM, White RM, Fitzpatrick JE, Kohout-Dutz, Rich Mond, et al. Cutaneous involvement of multiple myeloma and extramedullary plasmacytoma. J Am Acad Dermatol. 1988; 19:879-90.

2. Daoud MS, Lust JA, Kyle RA, Pittelkow MR. Monoclonal gammapathies and associated skin disorders. J Am Acad Dermatol. 1999;40:507-35.

3. Requena L, Kutzner H, Palmedo G, Calonje E, Requena $C$, Pérez $G$, et al. Cutaneous involvement in multiple mieloma. Arch Dermatol. 2003;139:47586.

4. Fitzhugh VA, Siegel D, Bhattacharyya PK. Multiple primary cutaneous plasmacytomas. J ClinPathol. 2008;61(6):782-3.

5. Comfere NI, Gonzalez Santiago TM, Peters MS, Knudson RA, Ketterling RP, Gibson LE. Cutaneous extramedullary plasmacytoma: clinical, prognostic, and interphase cytogenetic analysis. Am J Dermatopathol. 2013;35(3):357-63.

6. Fitzhugh VA, Siegel D, Bhattacharyya PK. Multiple primary cutaneous plasmacytomas. J Clin Pathol. 2008;61(6):782-3.

7. Pereira MA, Baudrier T, Costa A, Magalhães J, Azevedo F. Cutaneous metastatic plasmacytomas with tropism for a previously injured limb. Dermatol Online J. 2008; 14:16

8. Pereira N, Brinca A, Tellechea O, Gonçalo M. Plasmocitoma cutâneo metastático em doente com mieloma múltiplo. Revista SPDV. 2012;70(3):38790. 